\title{
INDIVIDUAL RISK AND MUTUAL INSURANCE ${ }^{1}$
}

\author{
By David Cass, Graciela Chichillisky, AND Ho-Mou Wu
}

\begin{abstract}
This paper examines how, in the presence of individual risk, economic efficiency can be achieved without an unrealistically large number of contingent claims. Market uncertainty is specified in such a way that general types of individual risk and collective risk are properly accounted for and so that, specifically, market clearing is always satisfied ex post as well as ex ante. We show that consistency of beliefs and optimality of allocation can be guaranteed with an appropriate array of pure Arrow securities to spread collective risk and mutual insurance policies to pool individual risk. When there is individual risk common to like groups of individuals, pooling risk by means of mutual insurance permits substantial economizing on market transactions, as compared to those required if dealing instead with the full complement of pure Arrow securities. We show that if there are $N$ households (consisting of $H$ types), each facing the possibility of being in $S$ individual states together with $T$ collective states, then ensuring Pareto optimality requires only $H(S-1) T$ independent mutual insurance policies plus $T$ pure Arrow securities. Our results also help to clarify the question of which missing markets may affect allocational efficiency.
\end{abstract}

KeYwORDS: Individual risk, collective risk, Arrow securities, Malinvaud policies, insurance, general equilibrium.

\section{INTRODUCTION}

IDIOSYNCRATIC OR INDIVIDUAL RISK is a pervasive phenomenon, as emphasized in the seminal studies by Arrow and Lind (1970) and Malinvaud (1972). Theoretically, in order to achieve full insurance or Pareto optimality in a world with individual risk, a very large variety of contingent claims is required. These earlier studies provided justification for simpler institutional structure by exploiting the law of large numbers. Here we probe further and investigate how Pareto optimal allocation can be achieved in a finite economy with extensive individual risk. For this purpose, we introduce a combination of Arrow securities and mutual insurance contracts, effectively melding the Arrow-Debreu model of complete contingent markets for aggregate uncertainty (Arrow (1953) and Debreu (1959)) with Malinvaud's model of segmented insurance markets for individual uncertainty. Our results show that the number of instruments required to achieve Pareto optimality is substantially smaller than that suggested by blindly applying the standard Arrow-Debreu analysis.

In the justly well-known study of individual risk by Malinvaud (1972), the ideal operation of a large but finite economy is approximated by introducing actuari-

\footnotetext{
${ }^{1}$ The proximate cause for our undertaking this project was a very spirited discussion between Cass and Chichilnisky concerning her joint work with Wu (1992). David Lane pointed out the connection between the formulation of individual risk which we utilize and similar ideas due to de Finetti (1964). We are grateful to Kenneth Arrow, Edmond Malinvaud, Guy Laroque, and three anonymous referees for helpful suggestions. We alone bear the collective risk for the subsequent outcome.
} 
ally fair insurance contracts, and then postulating that materials balance or market clearing need only hold in the sense of expected value. The basic shortcoming with such an approximation is pretty clear: since (average) market clearing ex ante does not ensure (specific) market clearing ex post, while, no matter how large the economy, the tail of the distribution across households has positive probability, the market may in reality perform very badly. Simply put, if each of $10^{n}$, say, otherwise identical households faces the independent prospect of being sick with probability $10^{-1}$, the probability that many more (or less) than $10^{n-1}$ households will be sick is still positive, no matter how large $n$. And, in that event, a market conceived to deal with only $10^{n-1}$ sick individuals would respond, at best, inefficiently, and, at worst, chaotically relative to the households' prior expectations. In this setting, in fact, Chichilnisky and Wu (1992) show that, even when just slightly more than 1 out of 10 households will default due to idiosyncratic risk, trade patterns among the households can lead to widespread default in the economy.

There are, however, ways of dealing with the source of such potentially unfavorable market outcomes. In particular, this objective can be achieved by expanding on another formalization of uncertainty by Malinvaud (1973, pp. 391-392) so that there is exact market clearing in the presence of individual cum social or collective risk. For-unlike a particular household being sick-some proportion of all households being sick involves a collective risk, a type of risk which Arrow (1953) and Debreu (1959) long ago demonstrated can be effectively accommodated by the competitive mechanism. This suggests that simply by introducing collective states corresponding to the different possible overall population realizations of individual risk-as well as an appropriate vartety of insurance contracts (written contingent on the joint individual-collective states) - we should be able to guarantee consistency of beliefs as well as optimality of allocation. The main contribution of this paper is to describe precisely such "an appropriate variety of insurance contracts," which is a combination of mutual insurance policies and pure Arrow securities.

Thus, in the following sections we essentially reformulate Malinvaud's nice original intuition with help from Arrow's famous earlier insight. It is shown that if there are $N$ households consisting of $H$ types, each facing the possibility of being in $S$ individual states together with $T$ collective states, then ensuring Pareto optimality requires only $H(S-1) T$ independent mutual insurance policies plus $T$ pure Arrow securities. To be more specific, continue with the previous example, where $H=1$ and $S=2$, so that $T=N+1$. In this case we show that, rather than a complete set of $2^{N}$ pure Arrow securities (corresponding to the, say, extensive social states distinguishing each individual's state of health), consistent decentralized sharing of the individual risks associated with being sick or well would only require $2(N+1)$ separate kinds of insurance contracts and Arrow securities. The number of financial instruments needs only to be a linear function, rather than an exponential function as with pure Arrow securities, of the number of households.

Our reformulation of uncertainty improves on Malinvaud's specification in two important respects: First, market uncertainty is specified in such a way that 
more general types of individual risk and collective risk are properly accounted for and so that, specifically, market clearing is always satisfied ex post as well as ex ante. Second, as we have already stressed, pooling of individual risk is accomplished by means of mutual insurance policies (each covering a particular joint state for a particular type of household), while spreading of collective risk is accomplished by means of pure Arrow securities (each covering a particular collective state for all types of households). But the bottom line is essentially intact: When there is anonymous individual risk common to like groups of individuals, pooling that risk by means of mutual insurance permits substantial economizing on market transactions-compared to those required if dealing instead with the full complement of pure Arrow securities.

\section{INDIVIDUAL RISK AND COLLECTIVE RISK}

There are $H$ types of households $(h=1,2, \ldots, H)$, and $N_{h}$ households of each type $h$, so that altogether there are $N=\Sigma_{h} N_{h}$ households. Each household of type $h$ faces two sorts of uncertainty, individual uncertainty, and collective uncertainty. There are $S$ possible individual states $(s=1,2, \ldots, S), T$ possible collective states $(t=1,2, \ldots, T)$. The household correctly believes that its probability of being in the joint state $(s, t)$ is given by $\pi_{h}(s, t)>0$, where $\Sigma_{s, t} \pi_{h}(s, t)=1$.

Following Malinvaud, what makes this a model of individual risk (as well as collective risk) is that, in fact, for the conditional probability

$$
\pi_{h}(s \mid t)=\pi_{h}(s, t) / \sum_{s^{\prime}} \pi_{h}\left(s^{\prime}, t\right),
$$

exactly $\pi_{h}(s \mid t) N_{h}$ households will find themselves in individual state $s$ when collective state $t$ occurs. It is assumed that the collective state $t$ includes the specification of the proportion of households in each individual state. In effect, nature draws randomly twice: first, to determine how many balls to take out of an urn, and then second, to determine which specific balls are actually withdrawn from the urn. Beforehand, the household can only reckon with-and therefore only cares about - the outcome of the first draw. Of course, more generally, the description of the collective states might well also encompass a good deal more than just what proportions of the households will find themselves in different individual states.

There are $C$ commodities in the economy $(c=1,2, \ldots, C)$, but no production; quantities of the goods are represented by the vector $x=\left(\ldots, x^{c}, \ldots\right)$. Each household of type $h$ has the consumption set $X_{h}=\left(\mathbb{R}_{++}^{c}\right)^{s T}$, certainty preferences represented by the utility function $v_{h}: \mathbb{R}_{++}^{c} \rightarrow \mathbb{R}$, and, depending on just its individual state, goods endowment $e_{h}(s)=\left(\ldots, e_{h}^{c}(s), \ldots\right) \in \mathbb{R}_{++}^{c}$, all $s . v_{h}$ is assumed to be twice continuously differentiable, differentiably strictly increasing (i.e., $D v_{h}(x) \gg 0$ for $x \gg 0$ ) and differentiably strictly concave (i.e., $\Delta x^{t} D^{2} v_{h}(x) \Delta x<0$ for $\left.x \gg 0, \Delta x \neq 0\right)$, and to have indifference surfaces with 
closure in $\mathbb{R}_{++}^{c}$. Finally, the household evaluates its contingent consumption plan, represented by the vector $x_{h}=\left(\ldots, x_{h}(s, t), \ldots\right)=$ $\left(\ldots,\left(\ldots, x_{h}^{c}(s, t), \ldots\right), \ldots\right)$, according to the expected utility function $u_{h}: X_{h} \rightarrow \mathbb{R}$ such that

$$
u_{h}\left(x_{h}\right)=\sum_{s, t} \pi_{h}(s, t) v_{h}\left(x_{h}(s, t)\right) .
$$

This is a fairly standard specification, except for the facts that (i) ex ante, the households of type $h$ are indistinguishable (each has exactly the same consumption set $X_{h}$, certainty preferences $v_{h}$, goods endowments $e_{h}=\left(\ldots, e_{h}(s, t), \ldots\right)$, and future uncertainty $\left.\pi_{h}=\left(\ldots, \pi_{h}(s, t), \ldots\right)\right)$, and (ii) ex post, for the households of type $h$, the population realization is equal to its conditional distribution (there are exactly $\pi_{h}(s \mid t) N_{h}$ households in state $s$ ). This general conception of individual risk, which could be aptly labelled ex ante anonymity, is closely related to de Finetti's notion of exchangeability (see, especially, de Finetti (1964)). It is also consistent with but not limited to each household of type $h$ facing an independent draw from an identical probability distribution over individual states. Of course, under such a standard interpretation the number of collective states is given by the combinatorial formula

$$
T=\prod_{h}\left(\begin{array}{c}
S+N_{h}-1 \\
N_{h}
\end{array}\right),
$$

so that, when $N_{h}$ is very large for all $h, T$ is also very large. This results from the fact that with independent, identically distributed individual uncertainty extremely unlikely events are necessarily included among the collective states. In contrast, the more general model of individual risk we have adopted here also permits, for example, focusing on the other polar or limiting case in which $T=1$.

\section{OPTIMAL ALLOCATION}

Now let $x=\left(\ldots, x_{h}, \ldots\right)$ represent an allocation of contingent consumption for the economy, where, in the usual fashion, all households of type $h$ are treated symmetrically. Then, $x$ is a feasible allocation if contingent consumption is feasible for each household, $x \gg 0$, and materials balance over all households,

$$
\sum_{h} N_{h} \sum_{s} \pi_{h}(s \mid t)\left(x_{h}(s, t)-e_{h}(s)\right)=0, \text { all } t .
$$

Moreover, adopting the ex ante viewpoint, $x$ is Pareto optimal if it is feasible, and there is no other feasible allocation $x^{\prime}$ which Pareto dominates it:

$$
u_{h}\left(x_{h}^{\prime}\right) \geq u_{h}\left(x_{h}\right) \text { for all } h \text {, and } u_{h}\left(x_{h}^{\prime}\right)>u_{h}\left(x_{h}\right) \text { for some } h .
$$

Let $\pi(t)=\pi_{h}(t)=\Sigma_{s} \pi_{h}(s, t)$, all $h, t$, denote the common probability of collective state $t$. Then $x$ is Pareto optimal if and only if there exist positive weights 
for each household type, $\mu_{h}=1 / \lambda_{h}>0$, all $h$, such that $x$ is the solution to the concave programming problem

$$
\begin{array}{ll}
\text { maximize } & \sum_{h} \mu_{h} N_{h} u_{h}\left(x_{h}\right) \quad\left(=\sum_{h} \mu_{h} N_{h} \sum_{s, t} \pi_{h}(s, t) v_{h}\left(x_{h}(s, t)\right)\right) \\
\text { subject to } & \sum_{h} N_{h} \sum_{s} \pi_{h}(s \mid t)\left(x_{h}(s, t)-e_{h}(s)\right)=0, \text { all } t, \text { and } x_{h} \gg
\end{array}
$$

Given our assumptions about the expected utility functions, the followin characterization of Pareto optimality can be easily established.

PROPOSITION: A feasible allocation $x$ is Pareto optimal if and only if there exist positive implicit values for each household type, $\lambda_{h}>0$, all $h$, and strictly positive contingent goods prices for each collective state, $p(t) \gg 0$, all $t$, such that

$$
\pi(t) D v_{h}\left(x_{h}(s, t)\right)-\lambda_{h} p(t)=0, \text { all } h, s, t .
$$

Notice that (3) entails that, say, $x_{h}(s, t)=x_{h}(1, t)$, all $h, s, t$, that is, that optimal allocation requires, conditional on the collective state, full insurance against all individual risk. The main purpose of the remainder of our paper is to show how to decentralize (1) and (3) using mutual insurance policies (written on $(s, t)$ ) together with pure Arrow securities (written on $t$ ).

\section{MUTUAL INSURANCE AND ARROW SECURITIES}

To begin with, observe that (1) and (3) constitute the essence of the description of a kind of equilibrium (labelled by Malinvaud (1973) as the " $B$-equilibrium"), one which is reminiscent of an Arrow-Debreu equilibrium. In this kind of equilibrium - for either a given endowment $e_{h}$ or an assigned endowment $e_{h}=x_{h}$ (corresponding to some particular Pareto optimal allocation)-(i) a household of type $h$ acts as if it faces individualized contingent goods prices of the form

$$
p_{h}(s, t)=\pi_{h}(s \mid t) p(t), \text { all } s, t,
$$

i.e., chooses contingent consumption as the optimal solution to the concave programming problem

$$
\begin{array}{ll}
\text { maximize } & u_{h}\left(x_{h}\right) \quad\left(=\sum_{s, t} \pi_{h}(s, t) v_{h}\left(x_{h}(s, t)\right)\right) \\
\text { subject to } & \sum_{s, t} P_{h}(s, t)\left(x_{h}(s, t)-e_{h}(s)\right)=0 \quad \text { and } \quad x_{h} \gg 0,
\end{array}
$$

and (ii) collective contingent goods markets clear, i.e.,

$$
\sum_{h} N_{h} \sum_{s} \pi_{h}(s \mid t)\left(x_{h}(s, t)-e_{h}(s)\right)=0, \text { all } t .
$$


To see this, simply associate the Lagrange multiplier $\lambda_{h}$ with the budget constraint in (4), and notice that here the Lagrange/Kuhn-Tucker Theorem also yields (3). But there is an obvious drawback to this application of the Two Basic Welfare Theorems. Such individual behavior as described in (4) does not at all clearly reflect transacting on any conceivably operative, even highly idealized, set of markets, in particular, the collective contingent goods markets themselves. We need somehow to elaborate the constraints in (4) so that it does.

Following the earlier leads of both Malinvaud and Arrow, one particularly appealing elaboration only requires introducing the two distinct types of insurance contracts emphasized previously. Thus, on the one hand, consider first the market opportunities for insuring the individual risk faced by the households of just type $h$. Suppose that these households can buy or sell units of each of $S T$ mutual insurance policies which pay a net benefit of $1-\pi_{h}(s \mid t)$ dollars if they find themselves in a joint state $(s, t)$, and carry a premium of $\pi_{h}(s \mid t)$ dollars in a joint state $\left(s^{\prime}, t\right)$ with $s^{\prime} \neq s$, but nothing otherwise, that is, in a joint state $\left(s^{\prime}, t^{\prime}\right)$ with $t^{\prime} \neq t$. Represent the level of such insurance by $m_{h}^{s, t}$, with $m_{h}=$ $\left(\ldots, m_{h}^{t}, \ldots\right)=\left(\ldots,\left(\ldots, m_{h}^{s, t}, \ldots\right), \ldots\right)$, and note that it is truly mutual: When all households of type $h$ purchase $m_{h}^{s, t}$ units, in collective state $t$ total net benefits will equal $\pi_{h}(s \mid t) N_{h}\left(1-\pi_{h}(s \mid t)\right) m_{h}^{s, t}$, while total premiums will also necessarily equal $\sum_{s^{\prime} \neq \mathrm{s}} \pi_{h}\left(s^{\prime} \mid t\right) N_{h} \pi_{h}(s \mid t) m_{h}^{s, t}=\pi_{h^{2}}(s \mid t) N_{h}\left(1-\pi_{h}(s \mid t)\right) m_{h}^{s, t}$. Also note explicitly that the $S T$ mutual insurance policies available to a household of type $h$ depend on collective as well as individual risk; this idealization of insurance contracts is analogous to Arrow's idealization of financial contracts.

Now, on the other hand, consider the market opportunities for insuring the collective risk faced by the households of all types. Suppose that, in addition to mutual insurance policies, the households can buy or sell units of each of $T$ pure Arrow securities which cost one dollar ex ante, and return one dollar if they find themselves in collective state $t$, but nothing otherwise. Represent the holding of such securities by $a_{h}^{t}$, with $a_{h}=\left(\ldots, a_{h}^{t}, \ldots\right)$, and note that each household's purchases must be balanced by its sales, both accounted for ex ante.

Given these opportunities, and correctly anticipating the spot goods prices $p$, a household of type $h$ chooses $\left(x_{h}, m_{h}, a_{h}\right)$ as the optimal solution to the concave programming problem

$$
\begin{aligned}
\text { maximize } & u_{h}\left(x_{h}\right) \quad\left(=\sum_{s, t} \pi_{h}(s, t) v_{h}\left(x_{h}(s, t)\right)\right) \\
\text { subject to } & p(t)\left(x_{h}(s, t)-e_{h}(s)\right)=\left(1-\pi_{h}(s \mid t)\right) m_{h}^{s, t} \\
& -\sum_{s^{\prime} \neq s} \pi_{h}\left(s^{\prime} \mid t\right) m_{h}^{s^{\prime}, t}+a_{h}^{t}, \quad \text { all } s, t, \\
& \sum_{t} a_{h}^{t}=0, \text { and } x_{h} \gg 0
\end{aligned}
$$


Then, in this setting, $p$ is an equilibrium (with rational expectations) if, when households optimize, the securities as well as the spot goods markets clear, i.e.,

$$
\sum_{h} N_{h} a_{h}^{t}=0, \text { all } t
$$

as well as (1) obtains. But notice that, as in Arrow's original analysis, the securities market clearing conditions are actually redundant: From the spot market budget constraints in (5)

$$
p(t)\left(x_{h}(s, t)-e_{h}(s)\right)=m_{h}^{s, t}-\sum_{s^{\prime}} \pi_{h}\left(s^{\prime} \mid t\right) m_{h}^{s^{\prime}, t}+a_{h}^{t}, \quad \text { all } s, t,
$$

or

$$
\begin{aligned}
\sum_{s} \pi_{h}(s \mid t) p(t)\left(x_{h}(s, t)-e_{h}(s)\right) \\
=\sum_{s} \pi_{h}(s \mid t) m_{h}^{s, t}-\sum_{s} \pi_{h}(s \mid t)\left[\sum_{s^{\prime}} \pi_{h}\left(s^{\prime} \mid t\right) m_{h}^{s^{\prime}, t}+a_{h}^{t}\right] \\
=\sum_{s} \pi_{h}(s \mid t) m_{h}^{s, t}-\sum_{s^{\prime}} \pi_{h}\left(s^{\prime} \mid t\right) m_{h^{\prime}, t}+a_{h}^{t} \\
=a_{h}^{t}, \quad \text { all } t .
\end{aligned}
$$

Hence we have

$$
p(t) \sum_{h} N_{h} \sum_{s} \pi_{h}(s \mid t)\left(x_{h}(s, t)-e_{h}(s)\right)=\sum_{h} N_{h} a_{h}^{t}, \quad \text { all } t,
$$

while from the spot goods market clearing conditions (1)

$$
p(t) \sum_{h} N_{h} \sum_{s} \pi_{h}(s \mid t)\left(x_{h}(s, t)-e_{h}(s)\right)=0, \text { all } t,
$$

which together entail (6). It therefore follows that the insurance opportunities represented in (5) would provide the desired elaboration of the market opportunities underlying (4) if, in terms of just contingent consumption, the two problems have identical constraint sets. So we have the following result.

THEOREM: Given $p \gg 0, x_{h}$ satisfies the constraints in (4) if and only if there are $m_{h}$ and $a_{h}$ such that $\left(x_{h}, m_{h}, a_{h}\right)$ satisfies the constraints in (5). In other words, in this context, mutual insurance and Arrow securities provide the necessary means for ensuring Pareto optimal allocation.

PROOF OF THE THEOREM: (Necessity): Suppose that $x_{h}$ satisfies the individualized contingent goods budget constraint in (4),

$$
\sum_{s, t} \pi_{h}(s \mid t) p(t)\left(x_{h}(s, t)-e_{h}(s)\right)=0 .
$$


Then define

$$
a_{h}^{l}=\sum_{s} \pi_{h}(s \mid t) p(t)\left(x_{h}(s, t)-e_{h}(s)\right), \text { all } t,
$$

so that, from (8), $\Sigma_{t} a_{h}^{t}=0$, i.e., $a_{h}$ satisfies the securities market budget constraint in (5). Now consider the equations (in the variables $m_{h}^{t}$ )

$$
m_{h}^{s, t}-\sum_{s^{\prime}} \pi_{h}\left(s^{\prime} \mid t\right) m_{h}^{s^{\prime}, t}=p(t)\left(x_{h}(s, t)-e_{h}(s)\right)-a_{h}^{t}, \quad \text { all } s \text { and } t,
$$

which can be rewritten in vector matrix form

$$
\left(I-\Pi_{h}^{t}\right) m_{h}^{t}=w_{h}^{t},
$$

where

$$
\Pi_{h}^{t}=\left[\begin{array}{c}
\pi_{h}^{t} \\
\vdots \\
\pi_{h}^{t} \\
\vdots
\end{array}\right] \quad \text { with } \pi_{h}^{t}=\left(\ldots, \pi_{h}(s \mid t), \ldots\right)
$$

and $w_{h}^{t}=\left(\ldots, p(t)\left(x_{h}(s, t)-e_{h}(s)\right)-a_{h}^{t}, \ldots\right)$. It is easily verified (by subtracting $\pi_{h}\left(s^{\prime} \mid t\right) / \pi_{h}(s \mid t)$ times row $s$ from each row $\left.s^{\prime} \neq s\right)$ that any $(S-1)^{2}$-dimensional submatrix of $I-\Pi_{h}^{t}$ obtained by deleting row and column $s$ has full rank $S-1$, and (by employing the definition of $a_{h}$ above) that

$$
\pi_{h}^{t}\left(I-\Pi_{h}^{t}\right) m_{h}^{t}=\pi_{h}^{t} w_{h}^{t}=0 .
$$

Hence, it follows that (9) has a solution, in fact, many solutions, parameterized, for example, by $m_{h}^{s, t}$. But simply rearranging (9) this means nothing more than that, for such solutions $m_{h},\left(x_{h}, m_{h}, \mathrm{a}_{h}\right)$ is also a solution to the spot market budget constraints in (5).

(Sufficiency) Suppose that $\left(x_{h}, m_{h}, a_{h}\right)$ with $x_{h} \gg 0$ satisfies both the securities and the spot market budget constraints in (5). Then just substituting from (7) into the securities market budget constraint immediately yields the individualized contingent goods budget constraint in (4).

Q.E.D.

\section{CONCLUDING REMARKS}

Once the conceptual foundation is in place, our theorem basically amounts to artfully merging Malinvaud's construction with Arrow's. Equation (10), in fact, exhibits the precise relationship between our mutual insurance policies and the appropriate version of Malinvaud's generalized insurance policies which permit actuarially fair transfer of wealth between the individual states $s$, conditioned on the collective state $t$. It also explains why, for each household type $h$ and collective state $t$, one of the mutual insurance policies is necessarily redundant. In any event, various combinations of these pure Malinvaud policies and pure 
Arrow securities could obviously be used to represent other, alternative institutional arrangements, for instance, secondary reinsurance contracts.

The main practical drawback to instituting any full complement of insurance contracts is the sheer potential number of independent instruments which would be required. Our results also help to clarify the assessment of which absences of contingent claims markets may lead to inefficient allocation. Studying the consequences of incompleteness - in the situation where there are individual as well as collective risks -involves further refinement and extension of an already rapidly growing literature (see, especially, the surveys by Geanakopolos (1990) and Cass (1991)), and is clearly an important direction for future research.

Finally, returning to the initial motivation for our undertaking this project, we should point out that all that is really required for "rational expectations" in this general setting - that is, for consistency of ex post with ex ante market clearing in the presence of individual risk per se-is a commonly held (and correct) perception of future spot goods market prices in the collective states naturally associated with individual risk. What we establish, in addition, is that then a suitable array of insurance and securities would provide the necessary means for ensuring optimal market allocation as well.

Dept. of Economics, European University Institute, and Dept. of Economics, University of Pennsylvania, Philadelphia, PA 19104, U.S.A.

Program on Information and Resources and Dept. of Economics, 405 Low Library, Columbia University, New York, NY 10027, U.S.A.

and

Dept. of Economics, National Taiwan University and Institute of Economics, Academia Sinica, Taipai, Taiwan.

Manuscript received August, 1993; final revision received November, 1994.

\section{REFERENCES}

ARROW, KENNETH J. (1953): "Le Role des Valeurs Boursieres pour la Repartition la Meilleure des Risques,": Econometrie, 41-47; English translation as "The Role of Securities in the Optimal Allocation of Risk-bearing," Review of Economic Studies (1964), 31, 91-96.

ARROW, KENNETH J., AND RoBERT C. LiND (1970): "Uncertainty and the Evaluations of Public Investments," American Economic Review, 53, 941-973.

CASS, DAvID (1991): "Incomplete Financial Markets and Indeterminacy of Competitive Equilibrium," Advances in Economic Theory, 6th World Congress, ed. by J. J. Laffont. London: MacMillan.

Chichilnisky, Graciela, AND Ho-MOU WU (1992): "Financial Innovation and Endogenuous Default in Incomplete Asset Markets," SITE Technical Report No. 50, Stanford University.

Debreu, Gerard (1959): The Theory of Value. New York: Wiley.

DE FINETTI, B. (1964): "Foresight: Its Logical Laws, Its Subjective Sources," in Studies in Subjective Probability, ed. by H. E. Kyburg Jr. and H. E. Smokler. New York: Wiley.

GEANAKOPOLOS, JOHN (1990): "An Introduction to General Equilibrium with Incomplete Asset Markets," Joumal of Mathematical Economics, 19, 1-38.

MALINVAUd, EDMOND (1972): "The Allocation of Individual Risks in Large Markets," Joumal of Economic Theory, 4, 312-328.

- (1973): "Markets for an Exchange Economy with Individual Risks," Econometrica, 41, 383-410. 